\title{
Diagnostic possibilities of a method of content analysis for therapy of women exhibiting codependency
}

\author{
Pavel N. Ermakov ${ }^{*}$, Vera S. Butenko², Anastasia S. Kolenova ${ }^{3}$, Oksana S. Saakyan ${ }^{1}$ \\ ${ }^{1}$ Southern Federal University, Academy of Psychology and Pedagogy, 344000 Rostov-on- \\ Don, Russian Federation \\ ${ }^{2}$ Rostov State Medical University, 344022 Rostov-on-Don, Russian Federation \\ ${ }^{3}$ Don State Technical University, Faculty "Psychology, Pedagogy and Defectology", \\ 344000 Rostov-on-Don, Russian Federation
}

\begin{abstract}
The article presents the results of a comprehensive study of psychological characteristics of the manifestation of co-dependent behavior of women. The novelty of the study lies in the development of psychodiagnostics criteria for identifying co-dependent behavior using the content analysis method, using the Thematic Apperceptive Test (TAT) tables with the aim of further developing a set of therapeutic measures. The study involved 152 women from the Rostov region of the Russian Federation aged 17 to 30 years, exhibiting varying degrees of codependence and living with a drug-dependent partner for at least 5 years. The study was carried out using standardized psychological tests and projective methods, which made it possible to identify the degree of manifestation of co-dependent behavior: test "The scale of co-dependence in relations (Spann - Fisher)" (adaptation Moskalenko); "Write a story" technique (stimulus material of tables 2, 4 and 6 of TAT. It has been established that content analysis allows us to determine qualitative differences in the degree of manifestation of co-dependent behavior, which we can identify and use in the initial stage of therapy with a co-dependent client, which means that it allows not only to quickly identify the condition, but also to determine its intensity.
\end{abstract}

\section{Introduction}

Co-dependent behavior is a learned form of behavior expressed in self-suppressing patterns, which subsequently leads to a decrease in the ability to initiate general participation in various social relationships [1].

At the moment, co-dependent behavior appears to be one of the most common reason for seeking psychotherapy. While for specialists it becomes relevant to identify reliable diagnostic techniques to study the features of this phenomenon [2]. In this regard, an attempt was made to identify prerequisites of co-dependent behavior using projective techniques, which formed the basis of a comprehensive study of respondents from different regions of the South of the Russian Federation [3; 4].

Considering the origin of co-dependence, it is customary to distinguish 3 factors: biological (characteristics of the reactions for each person to various stimuli and effects) [5];

\footnotetext{
${ }^{*}$ Corresponding author: paver@sfedu.ru
} 
psychological (including personality traits, the presence of psychological trauma at different age periods) [6]; interactions with other people (both intrafamily and social) [7].

The psychological literature describes co-dependent personalities as people who grew up in single-parent family or in a family where one parent was addicted to psychoactive substances (alcohol and/or drugs); have various relationships with addicts; survivors of childhood violence (physical, sexual, emotional) [8].

In modern literature, it is customary to consider the phenomenon of "co-dependence" as a result of adaptation to past experience. When choosing a partner, co-dependent, sometimes unconsciously, makes a choice in favor of an addictive partner, because they see in him patterns of behavior to which they once learned to "successfully" adapt. At the same time, in the rehabilitation of alcohol or drug addicts, there are often cases of relapse provoked by the co-dependent partners, although they themselves is trying to "cure" the addictive patient [9; $10]$.

Co-dependent behavior is characterized by various psychological features of the manifestation: hypercontrol of yourself and Significant Other, not only in behavior, but also in feelings and thoughts $[11 ; 12]$; strictness towards yourself and others; inadequate selfesteem and uncontrolled desire to please others; fear of criticism and harsh reactions to it; uncontrolled fantasies and the need for deception, even without sufficient reasons; the need to feel "necessary and important"; never-ending feeling of guilt and shame for yourself and the Others [13].

The prevalence of psychological protective mechanisms in co-dependent patients is observed: denial, rationalization, alexithymia, denial in the form of the lack of awareness of their reactive actions, as well as the presence of an illusion of irreplaceability, lack of motive for self-development [14].

\section{Research methods}

1. Theoretical analysis of relevant scientific literature.

2. The method of psychological testing: test "The scale of co-dependence in relations (Spann - Fisher)" (adaptation Moskalenko); "Write a story" technique (stimulus material of tables 2, 4 and 6 of "Thematic Apperceptive Test" (TAT) $[15 ; 16]$.

3. Statistical data processing methods were carried out using the STATISTICA 10.0 software package.

To identify personality fixations and self-esteem we used the "Write a Story" technique (tables 2, 4 and 6 of TAT), which allow us to determine personal motives and orientations. For us it is extremely important that this technique allows the self-identification of respondents with the main character, the character becomes a component of their own "Self" in the specific situation of the story.

The interpretation of the test is based on the understanding that the image that appears in our consciousness in the first fractions of a second after the presentation of the picture triggers an avalanche of associations. An attempt to structure these associations into a framed sentence helps to express the most important "painful" for the author. Thus, a content analysis reveals a symptom of personality orientation. Analyzing the plots of all 4 stimulus materials, we get the opportunity to talk about the syndrome of co-dependent personality.

\section{Sample description}

The empirical study was conducted among co-dependent women aged 17 to 30 years who live with drug addicts (showing co-dependent behavior) and sought psychological help in overcoming difficulties in family relationships. Their addictive partners have a history of 
substance abuse for 3 months to 6 years (2.3 years in average) and have been treated in rehabilitation centers in the Rostov Region. In total, an empirical study involved 152 codependent women. Participation in the study of all respondents was voluntary.

\section{Research results}

According to the data obtained among the total number of participants in our study, the normative level regarding the presence of the fact of co-dependence was diagnosed in 42 women, accounting for $27.3 \%$. 66 women, representing $44.7 \%$ of the total sample, were diagnosed with a moderate rate of co-dependence, and 44 women, representing $28 \%$ of the total number of respondents, showed a high level of co-dependence (Figure 1).



Fig. 1. The level of severity of co-dependence among the entire sample (\%)

Based on the presented data, we can state that the following symptoms at varying degree are observed in women with co-dependent behavior: the presence of compulsive actions, guilt, complete surrender to Significant Other, delusion, restrained anger, denial, self-deception, constraint of feelings, low self-esteem, uncontrollable aggression, anger towards oneself, ignoring personal needs, as well as various communication problems.

Within the content analysis of stories ("Write a Story" technique), we identified the assessment criteria and were able to present it in the form of the following leading determinants of personality orientation:

- Focus on organization, creation;

- Focus on the object;

- Focus on each other;

- Lack of object relationships;

- Unrealistic expectations;

- Dissatisfaction with others;

- Merger, lack of boundaries;

- Need for approval;

- Perspective in time;

- Overcoming difficulties;

- Hope.

The results of a comparative analysis of the selected assessment criteria by the frequency of occurrence in respondents from different subgroups are presented in Table 1. 
Table 1. Leading determinants of personality orientation in the studied sample (ranked by frequency of occurrence)

\begin{tabular}{|c|c|c|c|}
\hline № & $\begin{array}{l}\text { Subgroup } 1 \text { - normative } \\
\text { level of co-dependence }\end{array}$ & $\begin{array}{l}\text { Subgroup } 2 \text { - moderate } \\
\text { level of co-dependence }\end{array}$ & $\begin{array}{c}\text { Subgroup } 3 \text { - high } \\
\text { level of co- } \\
\text { dependence }\end{array}$ \\
\hline 1 & $\begin{array}{l}\text { Focus on organization, } \\
\text { creation }\end{array}$ & Overcoming difficulties & $\begin{array}{l}\text { Overcoming } \\
\text { difficulties }\end{array}$ \\
\hline 2 & Focus on the object & Perspective in time & Perspective in time \\
\hline 3 & Overcoming difficulties & Focus on the object & Hope \\
\hline 4 & Hope & Dissatisfaction with others & $\begin{array}{l}\text { Merger, lack of } \\
\text { boundaries }\end{array}$ \\
\hline 5 & Perspective in time & Merger, lack of boundaries & $\begin{array}{c}\text { Dissatisfaction with } \\
\text { others }\end{array}$ \\
\hline 6 & Lack of object relationships & Hope & Need for approval \\
\hline 7 & Focus on each other & $\begin{array}{l}\text { Focus on organization, } \\
\text { creation }\end{array}$ & Focus on the object \\
\hline 8 & Unrealistic expectations & Need for approval & $\begin{array}{l}\text { Lack of object } \\
\text { relationships }\end{array}$ \\
\hline 9 & Dissatisfaction with others & Lack of object relationships & $\begin{array}{c}\text { Focus on } \\
\text { organization, } \\
\text { creation }\end{array}$ \\
\hline 10 & Need for approval & Unrealistic expectations & Focus on each other \\
\hline 11 & Merger, lack of boundaries & Focus on each other & $\begin{array}{c}\text { Unrealistic } \\
\text { expectations }\end{array}$ \\
\hline
\end{tabular}

Figure 2 graphically shows the results of the frequency analysis, which illustrates the quantitative changes in data for several groups of patterns (Figure 2):

- Frequency of occurrence of the main determinants - "Focus on organization, creation", "Lack of object relationships", "Unrealistic expectations", "Merging, lack of boundaries", "Need for approval", "Need for approval", "Overcoming difficulties", "Hope" in all subgroups is directly proportional to the increase in the level of co-dependence;

- In the subgroup 2 (moderate level of co-dependence) determinants "Focus on the object" is much more common than in the subgroup 1 and the subgroup 3;

- The frequency of occurrence of the determinant "Dissatisfaction with others" in subgroup 2 is similar to that in the subgroup 1 and significantly differs between subgroup 2 and subgroup 3;

The determinant "Overcoming difficulties", which indicates the willingness of respondents from groups 3 and 2 to see difficulties in all situations and overcome them, turned out to be the most pronounced indicator for the co-dependence; these cognitive bias can lead to a tendency to invent difficulties where they do not exist.

To determine the level of statistical significance of the obtained results, the Kruskal-Wallis test was used (using the Statistical Processing System R). It was found that the experimental groups have significant differences in performance. For the subsequent determination of the specificity of the differences of the variables in the 3 studied subgroups, a comparison was made using the multiple comparison method for posterior data analysis (Conover test). 


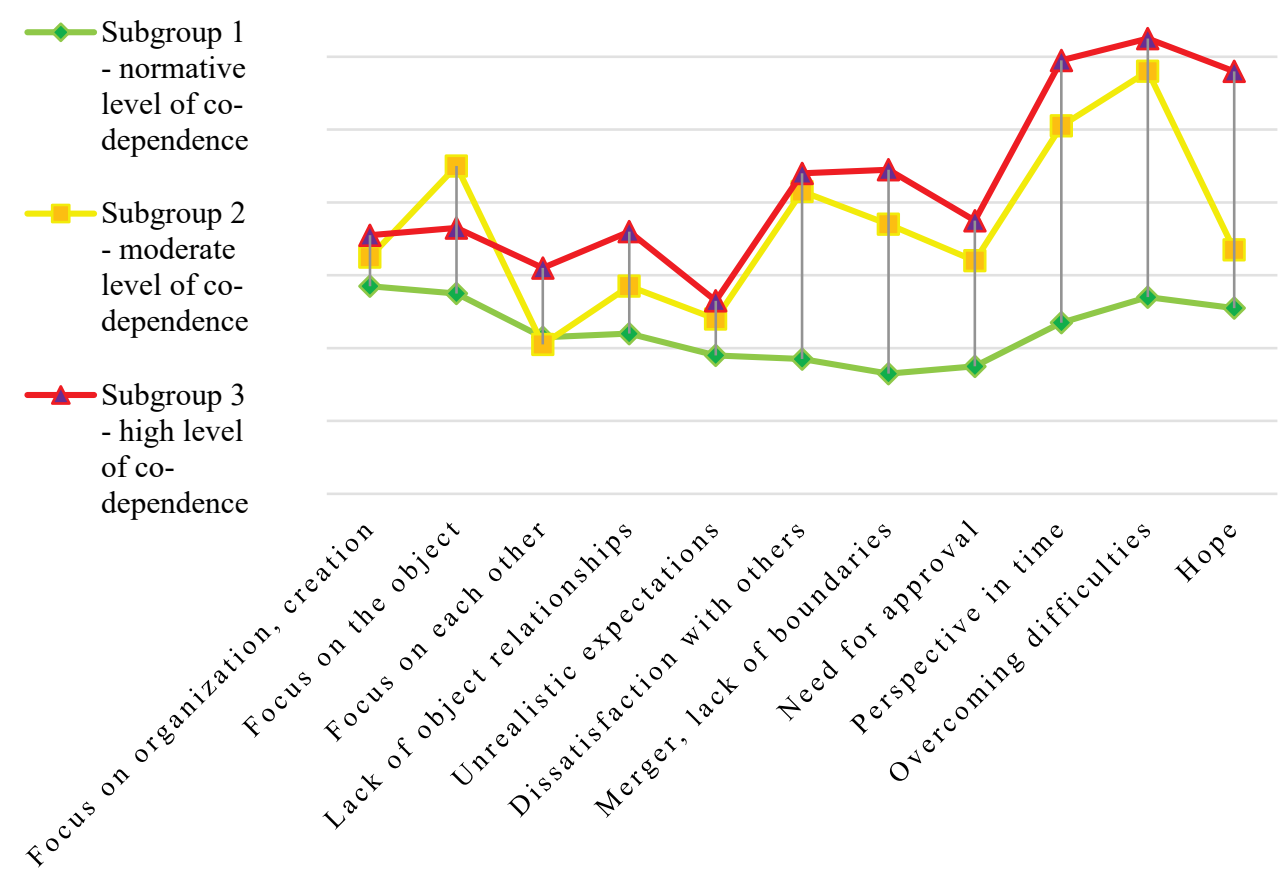

Fig. 2. General groups trends of personality orientations (frequency of occurrence)

Thus, 3 groups of statistically significant indicators were identified:

- A equable change in the criterion in all 3 subgroups is observed for "Need for approval" ( $p$ $<0.001)$, "Perspective in time" ( $p<0.001)$, "Overcoming difficulties" $(p<0.001)$, which indicate the motives of the activities of the co-dependent in the need for the approval from the people around them, the understanding that it is necessary to wait out certain negative events and positive changes will soon come, and there is also a tendency to see and overcome difficulties in any situations;

- Variance of the criterion is significant between subgroups 1 and 3, as well as 2 and 1, but it is not significant between subgroups 2 and 3 in the indicators "Dissatisfaction with others" $(p<0.001)$, "Merger, lack of boundaries" $(p<0.001)$, "Hope" $(p<0.001)$. So, they may indicate the presence of co-dependence, but not determine the degree of its severity;

- Indicators of the determinants "Orientation to the object" $(p<0.005)$ and "Orientation to each other" ( $p<0.001)$ are statistically significant in subgroups 1,2 and 3 , but they differ in subgroups 3 and 1 , which gives us the right to assume that these determinants can characterize the subgroup 2 - moderate level of co-dependence.

\section{Conclusions}

Based on the obtained data and analysis, the following conclusions were made:

1. With moderate co-dependence, women are characterized by the need to search for a problem or a "trick" in everything and everywhere, there is a belief that nothing is given for nothing, but only through hard work; other people appear to be hostile; they need to constantly receive approval from society; the expectation is that someday everything will change and improve; problems of the dependent partner are perceived as problems of the codependent, his value is perceived as a value of the co-dependent, etc. 
2. At the same time, in people with high level of co-dependence, these indicators are more pronounced, but the focus on the very cause of addictive behavior - the psychoactive substance - disappears. This indicates that the co-dependent ceases to direct its own efforts to effective assistance to addictive partner and closes in itself.

Thus, content analysis allowed us to identify qualitative differences in the degree of manifestation of co-dependent behavior. We can identify these differences during the first session with a co-dependent client, which means we get the opportunity to a more effective design therapeutic program.

This research was funded by the Russian Foundation for Basic Research (RFBR), project № 18-01301209.

\section{References}

1. E. Larsen, Stage II Recovery: Life Beyond Addiction (1985)

2. S. Karpman, A Game Free Life (2014)

3. F.E. Vasilyuk, Journal of Russian \& East European Psychology, 52(1), 1-58 (2015)

4. I.V. Abakumova, P.N. Ermakov, Voprosy psikhologii, 3, 78-82 (2003)

5. R.F. Bornstein, American Psychologist, 61(6), 595-606 (2006)

6. M. Beattie, Beyond codependency: And getting better all the time (1989)

7. P. Denning, Journal Clinical Psychology, 66(2), 164-174 (2010)

8. A.V. Merinov, D.I. Shustov, I.A. Fedotov, Rossiiskii Mediko-Biologicheskii Vestnik Imeni Akademika I.P. Pavlova, 19(3), 136-141 (2011)

9. M.C. Wells, M.B. Hill, G. Brack, C.J. Brack, E.E. Firestone, Journal of College Student Psychotherapy, 20(4), 71-84 (2006)

10. S. Sarkar, M.S. K.attoo, D. Basu, J. Gupta, International Journal of Culture and Mental Health, 8(1), 13-21 (2015)

11. M.C. Wells, M.B. Hill, G. Brack, C.J. Brack, E.E. Firestone, Journal of College Student Psychotherapy, 20(4), (2006)

12. T.M. Knudson, H.K. Terrell, The American Journal of Family Therapy, 40(3), 245-257 (2012)

13. C.L. Whitfield, Codependence: Healing the human condition: The new paradigm for helping professionals and people in recovery (1991)

14. E. Young, Journal of Psychoactive Drugs, 19(3), 257-268, (1987)

15. V.A. Soldatkin, Clinical psychometrics (2015)

16. E.V. Lanovoy, Method "Write a story: diagnosis, therapy and prognosis" (2006) 